\title{
OMEGA-3 FATTY ACIDS AND VITAMIN D IN IMMOBILISATION: PART B- MODULATION OF MUSCLE FUNCTIONAL, VASCULAR AND ACTIVATION PROFILES
}

\author{
E.L. BOSTOCK, C.I. MORSE, K. WINWOOD, I.M. MCEWAN, G.L. ONAMBÉLÉ \\ Health, Exercise and Active Living Research Centre, Department of Exercise \& Sport Science, Manchester Metropolitan University, Crewe Green Road, Crewe, United Kingdom. \\ Corresponding author: Gladys Onambele-Pearson, Health, Exercise and Active Living Research Centre, Department of Exercise \& Sport Science, Manchester Metropolitan University, \\ Crewe Green Road, Crewe, CW1 5DU, United Kingdom. Tel: +44 (0) 161247 5594; Email: g.pearson@mmu.ac.uk
}

\begin{abstract}
Objectives: This study set out to determine whether two potential protein-sparing modulators (eicosapentaenoic acid and vitamin D) would modulate the anticipated muscle functional and related blood vessels function deleterious effects of immobilisation. Design: The study used a randomised, double-blind, placebo-controlled design. Setting: The study took part in a laboratory setting. Participants: Twenty-four male

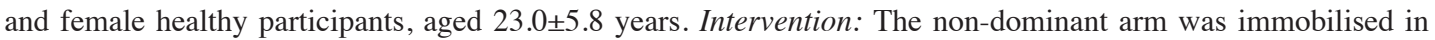
a sling for a period of nine waking hours a day over two continuous weeks. Participants were randomly assigned to one of three groups: placebo $(n=8$, Lecithin, $2400 \mathrm{mg}$ daily), omega-3 ( $\omega-3)$ fatty acids $(n=8$, eicosapentaenoic acid (EPA); $1770 \mathrm{mg}$, and docosahexaenoic acid (DHA); $390 \mathrm{mg}$, daily) or vitamin D (n=8, 1,000 IU daily). Measurements: Isometric and isokinetic torque, antagonist muscle co-contraction (activation profile), muscle fatigability indices, and arterial resting blood flow were measured before, at the end of the immobilisation period, and two weeks after re-mobilisation. Results: Muscle elbow flexion and extension isometric and isokinetic torque decreased significantly with limb immobilisation in the placebo group $(\mathrm{P}<0.05)$. Despite no significant effect of supplementation, $\omega-3$ and vitamin $\mathrm{D}$ supplementation showed trends $(\mathrm{P}>0.05)$ towards attenuating the decreases observed in the placebo group. There was no significant change in muscle fatigue parameters or co-contraction values with immobilisation and no effect of supplementation group $(\mathrm{P}>0.05)$. Similarly, this immobilisation model had no impact on the assessed blood flow characteristics. All parameters had returned to baseline values at the re-mobilisation phase of the study. Conclusion: Overall, at the current doses, neither $\omega-3$ nor vitamin D supplementation significantly attenuated declines in torque associated with immobilisation. It would appear that muscle function (described here in Part B) might not be as useful a marker of the effectiveness of a supplement against the impact of immobilisation compared to tissue composition changes (described in Part A).
\end{abstract}

Key words: Eicosapentaenoic acid, vitamin D, immobilisation, EMG, fatigability.

\section{Introduction}

Skeletal muscle adapts to environmental changes and differing levels of physical activity. Periods of disuse, where prolonged reductions in muscle activity and mechanical loading occur, result in profound changes in skeletal muscle morphology and strength in addition to bone parameters. It has consistently been demonstrated, that disuse models, including immobilisation, bed-rest and limb-suspension result in skeletal muscle atrophy (1-3), a decrease in maximal voluntary strength (1-3), and changes in electromyographic characteristics (4). Numerous studies have also documented the effects of immobilisation models on muscle fatigability, with equivocal findings of both decreased, increased and no change in resistance to fatigue $(3,5,6)$. With progressing fatigue, there is a shift in electromyography (EMG) to lower frequencies, and median power frequency can be used as an indices of this frequency shift. A decrease in the median power frequency serves as an index of fatigue $(7,8)$. Fast Fourier transform (FFT) of EMG produces a discrete-time, discrete-frequency representation and can be used to determine median power frequency. There are also several reports of the impact of disuse on the cardiovascular system with reports of decreased reactive hyperaemic blood flow (9-11). Early research demonstrated that static muscular contractions were accompanied by a marked impairment in blood flow to exercising muscles (12). Since then impaired blood flow has been used as an explanation for muscle fatigue during isometric contractions. Local changes in vascular dimensions and blood flow characteristics have been shown in response to resistance training, with de-training resulting in a worsening in theses parameters (beyond pretraining values) (13). Therefore, decreased loading with disuse, may negatively impact on vascular structure and function.

The ever-increasing population of frail elderly puts a strain on healthcare services. Indeed, prolonged sedentarism/ hypo-activity as may be encountered in enforced bed rest, immobilisation owing to orthopaedic clinic events, or simply even, decreased habitual physical activity, all show a high incidence in older persons (14-18). A common and serious problem for older adults is falls, with polypharmacy and some medications contributing to falls in many patients (19). This factor however, is remediable and non-pharmacological interventions are needed to prevent the age-associated loss in muscle size and function. Exercise could be beneficial in these 
circumstances but is not always a practical prescription; and as such, nutritional interventions could be key.

Vitamin D is required to absorb calcium and phosphorus in the body and has been shown to have a direct effect on muscle (20). Vitamin D plays a vital role in bone maintenance, muscle function, neuromuscular and immune functions, modulation of cell growth and reduction of inflammation. The main source of vitamin $\mathrm{D}$ is from sunlight on the skin, with smaller amounts consumed in certain foods. Another way of making sure that the Recommended Dietary Allowance for vitamin D of 600 IU/day (21) is met, is through vitamin D supplementation. Research has demonstrated that vitamin D impacts on both the trans-membranous flows of calcium and phosphate in skeletal muscle, and the synthesis rate of contractile properties (22). Furthermore, research has indicated an association between genetic variation in the vitamin D receptor gene and muscle strength, fat mass and body mass in premenopausal women (23). Vitamin D supplementation in frail elderly women with vitamin D deficiency reduced falls by $49 \%$ and improved musculoskeletal function (24). It remains to be seen, in a healthy population with no known vitamin D deficiency, whether vitamin D supplementation would positively affect the response of muscle structural and contractile properties to immobilisation.

Another non-pharmacological agent that may help attenuate the changes associated with immobilisation is Eicosapentaenoic acid (EPA). EPA is an n-3 polyunsaturated fatty acid with antiinflammatory properties, which is synthesised from ingested alpha-linolenic acid or consumed in fish or in fish oil. Adequate intake (AI) for EPA is set at 1.6 and $1.1 \mathrm{~g} /$ day for men and women, respectively (25). Magee et al. suggested that EPA might reduce the pro-inflammatory cytokines associated with inflammation (26). They demonstrated in vitro that EPA inhibits the effects of TNF- $\alpha$ by reducing its apoptotic effects and enabling myogenesis (26). Previous research has suggested the potential of EPA to increase isometric and isokinetic torque (27). It is unclear whether this supplement would have a beneficial effect during immobilisation, where it is generally accepted that there is muscle atrophy (28), which is associated with decreased protein synthesis (29), but scant evidence for increased protein breakdown (30).

As described in Part A (i.e. our previous study), an arm immobilisation model was chosen as it is relatively less restraining on daily life and causes less burden on participants. In Part A, whilst there was no significant effect of supplement group on muscle size decreases with immobilisation, a nonsignificant trend for lesser atrophy in the treatment groups was seen. Based on the greater decline in muscle strength (due to the combined effects of neural and muscle components) with disuse, it is possible that functional measures are more sensitive to immobilisation than structural changes. Thus, it is possible, that EPA and vitamin D may preserve muscle function to a greater extent than a placebo over the period of immobilisation. The research question, therefore, was: what role, if any, have vitamin D or EPA supplementation in attenuating the changes associated with limb immobilisation? To answer this research question, isometric and isokinetic torque, agonist co-contraction, muscle fatigability and resting arterial blood flow markers, were systematically monitored, immediately post-immobilisation and post-remobilisation, to compare against status pre-immobilisation. Study participants received either $\omega-3$ (a fish oil of a complex of EPA and docosahexaenoic acid (DHA)), vitamin D or a placebo (Lecithin). Hereafter, these agents are simply referred to as EPA, vitamin D or placebo supplementation. It was hypothesised that muscle function will decrease, muscle co-contraction characteristics will worsen, and indices of healthy vascular function will deteriorate, with limb immobilisation. It was also hypothesised that EPA would be the most successful supplement at minimising these changes, as it acts on the protein synthesis pathways.

\section{Methods}

\section{Participants \& Study Design}

Participant inclusion and criteria were as described in study Part A. Briefly, twenty-four healthy volunteers participated in the study, following appropriate ethical approval, and then randomly assigned to one of three groups (PLA: $n=8$ (6 females, 2 males); EPA: $n=8$ (4 females, 4 males); Vit-D: $\mathrm{n}=8$ (5 females, 3 males $)$ ). The study used a randomised, double-blind, placebo-controlled design with the placebo group consuming $1464 \mathrm{mg}$ Soya Lecithin (Holland \& Barrett, UK) daily, the Vit-D group consuming 1,000 IU of Vitamin D3 (Now Foods Bloomingdale, U.S.A.) daily, and the EPA group consuming $1770 \mathrm{mg}$ EPA plus $390 \mathrm{mg}$ docosahexenoic acid (MorEPA, Minami Nutrition, UK), daily.

Participants attended a familiarisation session at least one week prior to the first testing session. After baseline testing, the non-dominant arm was immobilised in a sling for a minimum of nine waking hours a day for two continuous weeks. The correct sling wearing procedure was demonstrated to each participant (Figure 1 of Part A), the removal of the sling was only permitted when necessary (e.g. driving, taking a bath/ shower etc.). The sling minimised any movement mediolaterally at the elbow and shoulder and participants were required to not contract the upper musculature (including the hands) during immobilisation hours. Measures of isometric and isokinetic elbow torque, EMG co-contraction, muscle fatigability and arterial dimensions and blood flow, were taken immediately before the immobilisation period (Pre), immediately after the immobilisation period (Post), and two weeks after remobilisation (Post2). During the immobilisation period participants completed a 3-day food diary, a daily activity log (including sling-wear hours) and wore a pedometer (Omron Walking style III step counter, Omron Healthcare Co., Ltd, Kyoto, Japan) to record the number of steps taken each day. The food diaries were analysed for macronutrient 
and micronutrient average intake using Microdiet Plus 1.2 (Microdiet, Downlee Systems Ltd, UK). Nutritional information and steps taken each day are reported in the results section of Part A.

\section{Dynamometry}

Isometric and isokinetic elbow torque were assessed using a Cybex dynamometer (Cybex, New York, USA). Participants were positioned as per the manufacturer's recommendations. Briefly, they were positioned in a supine position with the axis of rotation of the dynamometer aligned with the anatomical axis of rotation of the elbow joint (lateral epicondyle).

\section{Isometric dynamometry}

Following a warm up at $60 \%$ sec at the participant's selfperceived $\sim 75 \%$ of maximum effort, two repetitions of isometric contractions were performed at six different elbow joint angles $\left(60^{\circ}, 70^{\circ}, 80^{\circ}, 90^{\circ}, 100^{\circ}\right.$ and $\left.110^{\circ}\right), 60$ seconds apart. Participants were instructed to rapidly exert maximal torque against the dynamometer lever arm over a 3-4 second period. First in flexion and, five seconds after return to baseline, in extension. Torque and angle were displayed on the screen of a computer (Macintosh G4; Apple Computer, Cupertino, CA), which was interfaced with an A/D system (Acknowledge, Biopac Systems, Santa Barbara, CA) with a sample frequency of $200 \mathrm{~Hz}$. Participants were encouraged to exert maximal torque with the use of visual and verbal feedback. Peak torque was averaged over a $500 \mathrm{~ms}$ period (i.e. $250 \mathrm{~ms}$ either side of the instantaneous peak). The highest of the repeated efforts was used as the participant's measure of MVC at each angle for elbow flexion and extension.

\section{Isokinetic dynamometry}

Isokinetic contractions were completed with three continuous elbow extensions and flexions at six different speeds $\left(30,60,90,120,180\right.$ and $\left.240^{\circ} / \mathrm{sec}\right)$ separated by 90 seconds, in a randomised order. The highest of the three consecutive efforts was recorded as peak torque $(25 \mathrm{~ms}$ either side of the instantaneous peak) for elbow extension and flexion at each speed.

\section{Electromyographic measurements}

Muscle activation patterns were assessed using EMG during the isometric and isokinetic contractions. The skin was prepared by shaving, abrading and cleaning with an alcoholwipe to minimise resistance below $5 \mathrm{k} \Omega$ (31). Self-adhesive electrodes were placed in pairs either side of the marker of a third of the distance along the biceps and triceps brachii, with reference electrodes placed on the lateral and medial epicondyle of the humerus. Raw EMG data were recorded at $2000 \mathrm{~Hz}$, with a band pass filter set at $10-500 \mathrm{~Hz}$, and a notch set at $50 \mathrm{~Hz}$ (Biopac Systems). Biceps co-contraction was calculated (biceps EMG during extension / biceps EMG during flexion) for both isometric and isokinetic contractions. Triceps co-contraction was also calculated (triceps EMG during flexion / triceps EMG during extension) again for both isometric and isokinetic contractions. Biceps and triceps EMG values were taken during the same windows as in isometric and isokinetic torque.

\section{Fatiguing contractions}

The dynamometer lever arm was locked at a $90^{\circ}$ angle (where $180^{\circ}$ is full elbow extension) and participants were required to exert a maximal isometric contraction in the direction of elbow flexion for 30 seconds. After 90 seconds of recovery, the participant then repeated the maximal isometric contraction for 30 seconds, this time in the direction of elbow extension. The mean, slope and standard deviation of the torque trace were recorded for the length of the 30-second contractions. FFT was computed for the agonist muscle during the first five and last five seconds of each fatiguing contraction. Median frequency values were determined for these time points and a change in median frequency was then computed as a measure of the fatigability of the muscle.

\section{Arterial resting blood flow}

After more than 20 minutes seated rest (following muscle ultrasound scans), allowing for the regulation of vascular tone, measurements in the sagittal plane of resting brachial artery diameter, heart rate (HR), resistance index (RI) and flow by diameter $(\mathrm{FbD})$ were obtained from the ultrasound software. The measurements were obtained using an echo Doppler ultrasound machine (AU5, Esaote, Genoa, Italy) with a 5.0- 13.0 MHz broadband linear array transducer (with settings of Doppler gain 37-41, angle of insonnation 60 degrees). The ultrasound probe was applied to the arm in line with the marker of the midpoint of the biceps brachii (as previously marked earlier for obtaining muscle ultrasound images). An average of nine cardiac cycles were acquired for all measurements, with the mean value reported.

\section{Statistics}

Data were analysed using IBM SPSS v21 (IBM Inc, USA). The Shapiro-Wilk test revealed some of the data to be nonparametric (EMG, fatigue, brachial artery diameter, HR and $\mathrm{FbD}$ values). The effect of immobilisation was examined by assessing the changes seen in the PLA group by either repeated measures ANOVA (parametric data) or a Friedman test (nonparametric data). Parametric percentage change values (Preto-Post: (Post-Pre)/Pre; and Pre-to-Post2: (Post2-Pre)/Pre) were analysed using a repeated measures ANOVA, with posthoc Bonferonni corrected 2-tailed t-tests to determine group difference. Non-parametric between group effect were analysed using the Kruskal Wallis test, with post-hoc the Mann-Whitney $\mathrm{U}$ tests. All data are presented as mean \pm standard deviation (SD). Statistical significance was set with alpha at $\leq 0.05$. 
Table 1

Fatigue characteristics in response to immobilisation and supplementation

\begin{tabular}{|c|c|c|c|c|}
\hline & & PLA & EPA & Vit-D \\
\hline \multicolumn{5}{|l|}{ Flexion } \\
\hline \multirow[t]{3}{*}{ Mean Torque (Nm) } & Pre & $26.2 \pm 12.7$ & $27.1 \pm 11.3$ & $28.4 \pm 10.8$ \\
\hline & Post & $24.5 \pm 12.1$ & $23.6 \pm 10.0$ & $26.8 \pm 10.9$ \\
\hline & Post2 & $25.8 \pm 12.1$ & $24.7 \pm 8.9$ & $26.8 \pm 11.4$ \\
\hline \multicolumn{5}{|l|}{ Flexion } \\
\hline \multirow[t]{3}{*}{ Standard Deviation } & Pre & $3.2 \pm 1.4$ & $3.4 \pm 1.3$ & $3.0 \pm 1.3$ \\
\hline & Post & $2.7 \pm 0.8$ & $2.9 \pm 1.4$ & $3.5 \pm 1.7$ \\
\hline & Post2 & $3.3 \pm 1.3$ & $2.7 \pm 1.3$ & $3.5 \pm 1.7$ \\
\hline \multicolumn{5}{|l|}{ Flexion } \\
\hline \multirow[t]{3}{*}{ Slope } & Pre & $-0.3 \pm 0.2$ & $-0.2 \pm 0.1$ & $-0.2 \pm 0.1$ \\
\hline & Post & $-0.3 \pm 0.2$ & $-0.2 \pm 0.1$ & $-0.3 \pm 0.2$ \\
\hline & Post2 & $-0.3 \pm 0.2$ & $-0.1 \pm 0.1$ & $-0.1 \pm 0.1$ \\
\hline \multicolumn{5}{|l|}{ Flexion } \\
\hline \multicolumn{5}{|l|}{ Agonist FFT } \\
\hline \multirow[t]{3}{*}{ 1st Five Seconds (Hz) } & Pre & $113.6 \pm 22.6$ & $102.9 \pm 8.5$ & $102.3 \pm 5.3$ \\
\hline & Post & $116.5 \pm 13.5$ & $106.5 \pm 7.8$ & $103.9 \pm 5.1$ \\
\hline & Post2 & $112.1 \pm 17.3$ & $103.7 \pm 8.0$ & $102.1 \pm 4.7$ \\
\hline \multicolumn{5}{|l|}{ Flexion } \\
\hline \multicolumn{5}{|l|}{ Agonist FFT } \\
\hline \multirow[t]{3}{*}{ Last Five Seconds (Hz) } & Pre & $115.2 \pm 16.7$ & $102.1 \pm 8.0$ & $104.2 \pm 9.5$ \\
\hline & Post & $119.1 \pm 15.8$ & $105.5 \pm 5.3$ & $105.6 \pm 8.5$ \\
\hline & Post2 & $113.6 \pm 12.7$ & $101.8 \pm 8.3$ & $104.2 \pm 9.2$ \\
\hline \multicolumn{5}{|l|}{ Extension } \\
\hline \multirow[t]{3}{*}{ Mean Torque (Nm) } & Pre & $20.4 \pm 14.4$ & $23.8 \pm 11.8$ & $21.9 \pm 12.1$ \\
\hline & Post & $19.2 \pm 13.5$ & $19.2 \pm 8.7$ & $17.7 \pm 10.2$ \\
\hline & Post2 & $21.3 \pm 12.1$ & $22.5 \pm 10.7$ & $22.3 \pm 9.6$ \\
\hline \multicolumn{5}{|l|}{ Extension } \\
\hline \multirow[t]{3}{*}{ Standard Deviation } & Pre & $2.9 \pm 1.9$ & $2.4 \pm 1.6$ & $2.2 \pm 1.3$ \\
\hline & Post & $2.5 \pm 1.5$ & $2.5 \pm 1.4$ & $2.1 \pm 0.9$ \\
\hline & Post2 & $2.8 \pm 2.1$ & $2.2 \pm 1.4$ & $2.1 \pm 1.1$ \\
\hline \multicolumn{5}{|l|}{ Extension } \\
\hline \multirow[t]{3}{*}{ Slope } & Pre & $-0.3 \pm 0.6$ & $0.1 \pm 0.1$ & $-0.2 \pm 0.3$ \\
\hline & Post & $-0.2 \pm 0.2$ & $-0.1 \pm 0.2$ & $-0.2 \pm 0.2$ \\
\hline & Post2 & $-0.3 \pm 0.4$ & $-0.1 \pm 0.3$ & $-0.1 \pm 0.1$ \\
\hline \multicolumn{5}{|l|}{ Flexion } \\
\hline \multicolumn{5}{|l|}{ Agonist FFT } \\
\hline \multirow[t]{3}{*}{ 1st Five Seconds (Hz) } & Pre & $131.8 \pm 13.6$ & $128.9 \pm 13.3$ & $131.5 \pm 9.7$ \\
\hline & Post & $132.6 \pm 16.5$ & $130.3 \pm 12.0$ & $133.2 \pm 13.2$ \\
\hline & Post2 & $142.3 \pm 15.8$ & $130.1 \pm 14.4$ & $131.7 \pm 9.9$ \\
\hline \multicolumn{5}{|l|}{ Flexion } \\
\hline \multicolumn{5}{|l|}{ Agonist FFT } \\
\hline \multirow[t]{3}{*}{ Last Five Seconds (Hz) } & Pre & $124.7 \pm 17.0$ & $124.1 \pm 16.0$ & $127.7 \pm 12.4$ \\
\hline & Post & $125.0 \pm 19.3$ & $125.7 \pm 15.3$ & $129.4 \pm 13.7$ \\
\hline & Post2 & $124.3 \pm 18.6$ & $125.1 \pm 15.9$ & $128.5 \pm 12.4$ \\
\hline
\end{tabular}

Mean values \pm SD for fatigue characteristics. The response of both the torque trace and fast Fourier transform of the agonist muscle during both a 30 second elbow flexion maximal fatiguing contraction and a 30 second elbow extension fatiguing contraction.

\section{Results}

\section{Baseline characteristics}

There were no significant differences in baseline characteristics (Table 1 of series A). Additionally, the groups did not differ in baseline isometric MVC elbow torque (e.g. isometric elbow torque at $90^{\circ}$ for flexion - PLA: $37.6 \pm 15.0$ Nm; EPA: $42.0 \pm 15.7$ Nm; Vit-D: $42.3 \pm 13.7$ Nm) EMG and fatigue values, or resting arterial blood vessel characteristics (vessel diameter - PLA: $3.3 \pm 0.5 \mathrm{~mm}$; EPA: $3.3 \pm 0.6 \mathrm{~mm}$; Vit-D: $3.2 \pm 0.3 \mathrm{~mm}$, HR - PLA: $69.6 \pm 11.6$ bpm; EPA: 68.5 \pm 12.1 bpm; Vit-D: $69.1 \pm 6.7$ bpm, RI - PLA: $0.7 \pm 0.3$; EPA: $0.8 \pm 0.1$; Vit-D: $0.9 \pm 0.1, \mathrm{FbD}-$ PLA: $0.11 \pm 0.05 \mathrm{~m} / \mathrm{s}$; EPA: $0.07 \pm 0.02 \mathrm{~m} / \mathrm{s} ;$ Vit-D: $0.06 \pm 0.03 \mathrm{~m} / \mathrm{s}$ ).

\section{Isometric dynamometry}

Isometric MVC torque decreased for both elbow flexion and extension at every angle $(\mathrm{p}<0.05)$ except for flexion at $110^{\circ}$ and extension at $100^{\circ}$ and $110^{\circ}$. Average isometric torque decrease from Pre to Post immobilisation across angles for flexion were $12.1 \pm 1.8 \%, 11.4 \pm 3.5 \%$ and $8.1 \pm 3.4 \%$, and for extension were $15.4 \pm 3.3 \%, 12.0 \pm 3.1 \%$ and $10.7 \pm 2.4 \%$, for PLA, EPA and Vit-D, respectively. There was no effect of group on the percentage change in isometric torque for flexion or extension at any of the six angles (Figure 1).

\section{Figure 1}

Isometric torque changes in response to immobilisation and supplementation



Pre (circles), Post (squares) and Post2 (triangles) values for isometric torque $(\mathrm{Nm} \pm \mathrm{SD})$ for elbow flexion $(\mathrm{a}=$ PLA; $\mathrm{b}=\mathrm{EPA} ; \mathrm{c}=\mathrm{Vit}-\mathrm{D})$ and elbow extension $(\mathrm{d}=\mathrm{PLA}$; $=$ EPA; $\mathrm{f}=\mathrm{Vit}-\mathrm{D})$ at the six different angles $\left(60-110^{\circ}\right) . *$ Significant difference between Pre and Post immobilisation in the PLA group. 


\section{Isokinetic dynamometry}

Isokinetic torque decreased significantly for both elbow flexion and extension at every speed $(\mathrm{p}<0.05)$ except for flexion at $90^{\circ} / \mathrm{sec}$. Average isokinetic torque decrease from Pre to Post immobilisation across speeds for flexion were 14.0 $\pm 4.5 \%, 8.6 \pm 1.3 \%$ and $7.8 \pm 5.5 \%$, and for extension were $10.3 \pm 1.8 \%, 8.1 \pm 0.9 \%$ and $7.1 \pm 1.8 \%$, for PLA, EPA and Vit-D, respectively. There was no effect of supplement group on the percentage change in isokinetic torque for flexion or extension at any of the six speeds. (Figure 2)

\section{Figure 2}

Isokinetic torque changes in response to immobilisation and supplementation

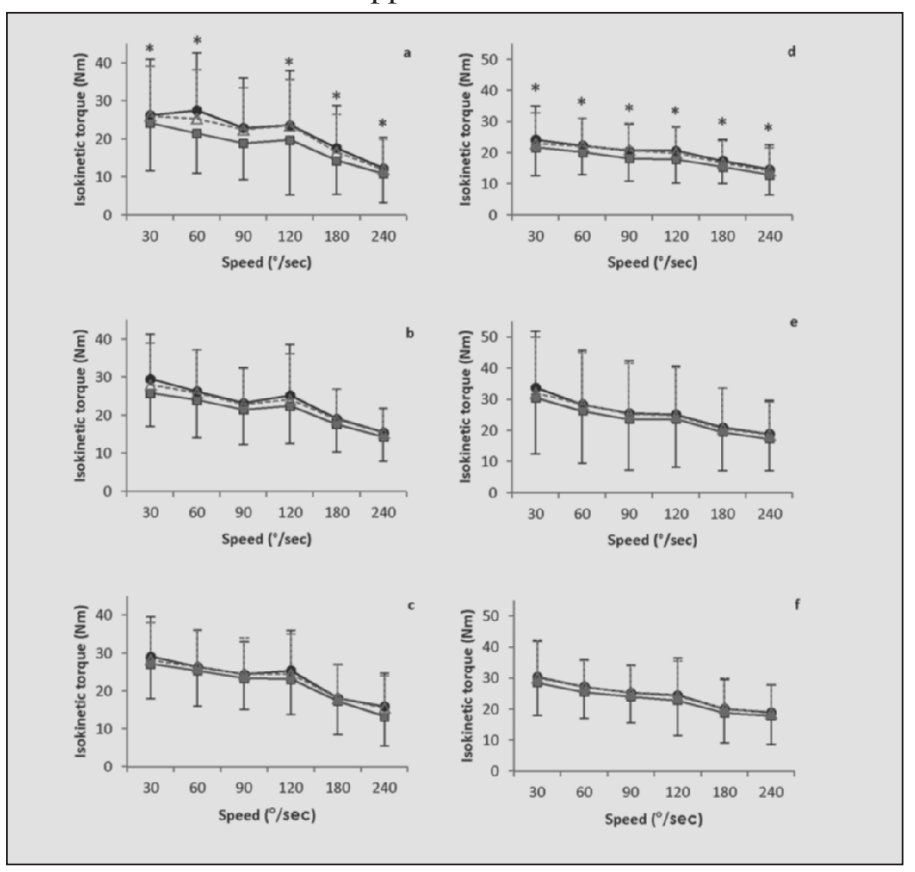

Pre (circles), Post (squares) and Post2 (triangles) values for isokinetic torque $(\mathrm{Nm} \pm \mathrm{SD})$ for elbow flexion $(\mathrm{a}=$ PLA; $\mathrm{b}=\mathrm{EPA} ; \mathrm{c}=\mathrm{Vit}-\mathrm{D})$ and elbow extension $(\mathrm{d}=\mathrm{PLA} ; \mathrm{e}=\mathrm{EPA}$; $\mathrm{f}=\mathrm{Vit}-\mathrm{D})$ at the six different speeds $\left(30-240^{\circ} / \mathrm{sec}\right)$. * Significant difference between Pre and Post immobilisation in the PLA group.

\section{Electromyographic measurements}

Analysis of biceps and triceps co-contraction RMS EMG values during the isometric contractions showed no significant changes from Pre to Post immobilisation and no effect of supplement group from Pre-to-Post and Pre-to-Post2 (Figure 3). Similarly, this was the case for the isokinetic contractions with no significant effect of immobilisation nor of supplement group on the EMG response to the immobilisation (Figure 4).

\section{Fatiguing contractions}

The mean, slope and standard deviation of the torque traces showed no significant changes with immobilisation phase for either flexion or extension fatiguing contractions, with no effect of supplement group on percentage changes. Analysis of the fast Fourier transformation of EMG traces of the biceps and triceps brachii revealed no significant effect of immobilisation or supplementation group on rate coding at either the beginning, or the end of a fatiguing maximal isometric contraction (Table 1).

\section{Figure 3}

Isometric bicep and triceps co-contraction changes in response to immobilisation and supplementation

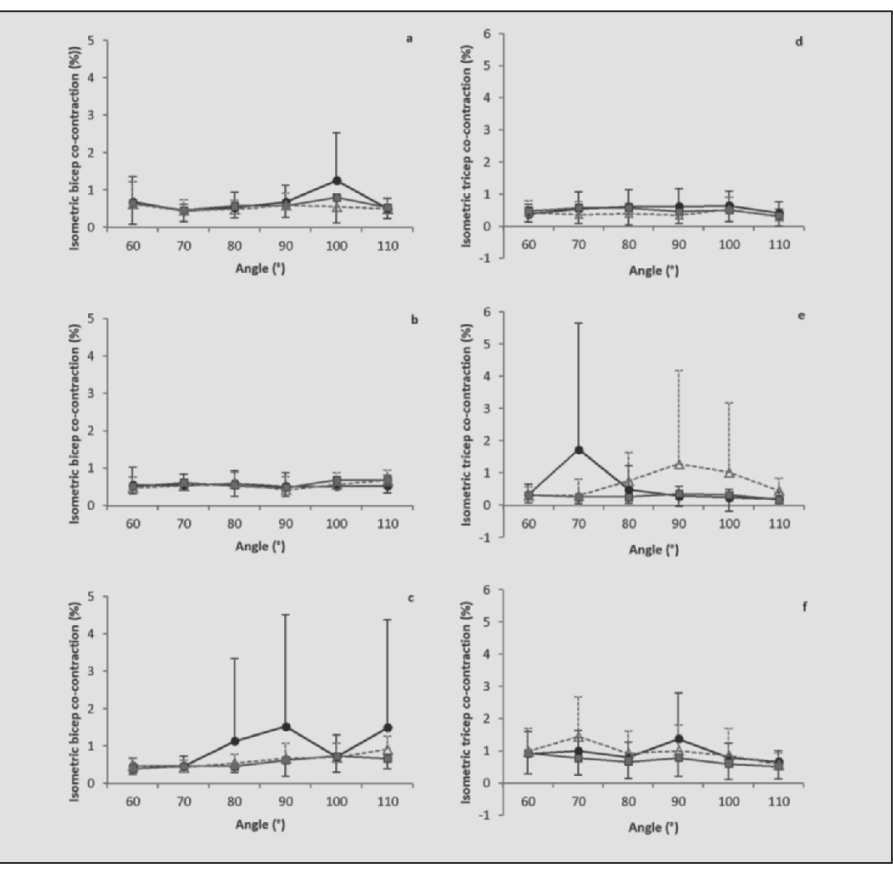

Pre (circles), Post (squares) and Post2 (triangles) values for co-contraction $(\mathrm{Nm} \pm \mathrm{SD})$ of the biceps $(\mathrm{a}=$ PLA; $\mathrm{b}=\mathrm{EPA} ; \mathrm{c}=$ Vit-D $)$ and triceps $(\mathrm{d}=$ PLA; $\mathrm{e}=\mathrm{EPA} ; \mathrm{f}=$ Vit-D $)$ during isometric elbow flexion and extension at the six different angles $\left(60-110^{\circ}\right)$.

\section{Arterial resting blood flow}

Brachial artery diameter, RI, FbD and HR did not change from Pre to Post immobilisation, nor Pre to Post2. There was no significant difference in the percentage change in brachial artery diameter, RI, FbD or HR between the groups (Table 2).

\section{Measurement reliability}

All protocols were assessed for intra as well as inter-day reliability. This utilised five participants and entailed carrying out measurements three times on day 1 , and repeating these on day 2, approximately a week later. Within-day coefficients of variation $(\mathrm{CV})$ of $1.8 \%, 2.0 \%, 1.5 \%, 5.4 \%, 2.4 \%$ and 12.0 $\%$, and between-day CVs of $2.5 \%, 2.3 \%, 2.3 \%, 8.1 \%, 4.0 \%$ and $9.1 \%$ were yielded for isometric torque, isokinetic torque, brachial artery diameter, HR, RI and FbD, respectively.

\section{Discussion}

We describe the effects of two potential protein-sparing modulators (EPA of vitamin D supplementations) on the response to 2 weeks of 9-waking-hours-per-day combined arm and shoulder immobilisation. We hypothesised that 
muscle function will decrease and muscle co-contraction characteristics will increase, and indices of healthy vascular function will deteriorate, with limb immobilisation. We found evidence to partially support our hypotheses, with significant immobilisation-induced decreases in isometric elbow flexion (PLA: 6.7 to $18.4 \%$ ) and extension (PLA: 8.7 to $13.8 \%$ ) torque, as well as isokinetic elbow flexion (PLA: 9.3 to $13.7 \%$ ) and extension (PLA: 9.8 to $18.1 \%$ ) torque. It was also hypothesised that EPA would be the most effective supplement at minimising the response to immobilisation. Our data demonstrate that neither EPA nor vitamin D had any significant effect on the responses to non-injurious immobilisation. Nonetheless, a few trends towards the attenuation of elbow isometric and isokinetic torque immobilisation-induced decreases were observed, in the EPA and Vit-D treated groups. We discuss the observed trends for the attenuation of these parameters. It is also notable that this immobilisation model had no impact on the assessed co-contraction and muscle fatigability, or on the assessed blood flow characteristics.

\section{Figure 4}

Isokinetic bicep and triceps co-contraction changes in response to immobilisation and supplementation

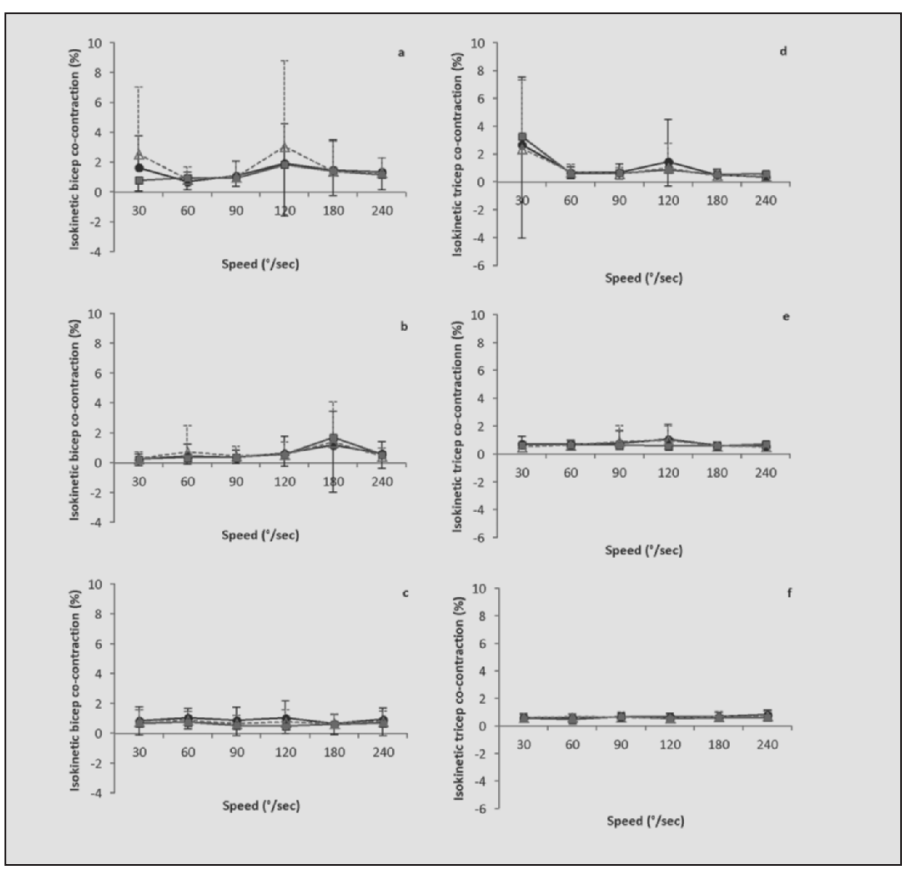

Pre (circles), Post (squares) and Post2 (triangles) values for co-contraction ( $\mathrm{Nm} \pm \mathrm{SD}$ ) of the biceps $(\mathrm{a}=$ PLA; $\mathrm{b}=\mathrm{EPA} ; \mathrm{c}=$ Vit-D $)$ and triceps $(\mathrm{d}=\mathrm{PLA} ; \mathrm{e}=\mathrm{EPA} ; \mathrm{f}=$ Vit-D $)$ during isokinetic elbow flexion and extension at the six different speeds $\left(30-240^{\circ} / \mathrm{sec}\right)$.

Isometric elbow extensor and flexor torque decreased following immobilisation. This supports previous findings of decreases in isometric MVC of the elbow flexors in response to 4 weeks of elbow cast immobilisation (6). In addition to the established decline in isometric torque, disuse models also result in reductions in dynamic torque outputs. Cast immobilisation of the arm (9 days) also results in decreased concentric and eccentric strength for flexion and extension of the wrist (3). Our current data also show a decrease in isokinetic strength for both elbow flexion and extension. However, muscle function in terms of isometric and/ or isokinetic torque, did not show a significant effect of either EPA or vitamin D supplementation at the current doses, in spite of somewhat blunting the effect of immobilisation, as this protective effect was not statistically significant.

Data collected for agonist and antagonist EMG activity highlighted no differences in biceps or triceps co-contraction following immobilisation. In contrasting, some of the previous research shows a large decrease in EMG amplitude measurements during flexion in both the agonist and antagonist muscle $(4,6)$. When drawing conclusions from EMG findings care should be taken, as: 1) the changes in muscle dimensions could result in a different population of motor units being recorded from (32); 2) EMG reliability in previously published studies is not very high, and this is a general limitation of studies utilising longitudinal EMG monitoring $(33,34)$. In addition, it is notable that EMG data in our, and previous work (31), does not normalise the data for the clarity of the signal. Specifically, we have recently demonstrated that sub-cutaneous adiposity changes with immobilisation (see study Part A of our current work), hence the electromyographic signature would have differed (35).

Numerous studies have documented the effects of immobilisation models on muscle fatigability, with equivocal findings of both decreased, increased and no change in resistance to fatigue $(3,5,6)$. In our current study, we found no significant changes in the mean, slope or standard deviation of the torque trace during the 30 s isometric contraction fatigue tasks that we implemented. Differences between studies could be due to the mode/duration of disuse or in the method used to test fatigue resistance since fibre recruitment level and pattern would vary with changes in contractile profile (36). The mechanisms behind the varying effects of immobilisation on muscle fatigability are yet to be fully explained. Our observation of no significant effect of immobilisation on the fast Fourier transformation of EMG traces at either the beginning or end of a maximal isometric contraction suggests no effect on motor unit rate coding and none on fibre type recruitment.

Previous research suggests that decreases in physical activity leads to detrimental vascular adaptations $(37,38)$. Bed-rest studies measuring leg blood flow report inconsistent results, with some showing no changes in leg blood flow and others demonstrating a decrease in leg blood flow after periods of bed rest (10-41 days) (38-41). None of these bed rest studies report data on changes in arterial vessel diameter. Studies investigating vascular changes in response to upper limb immobilisation are lacking. We report no significant dimensional changes in vasculature with upper limb immobilisation. Similarly, we observed no significant changes in resting HR in response to immobilisation. Equally, 
Table 2

Changes in blood kinetic parameters in response to immobilisation and supplementation

\begin{tabular}{lcccccc}
\hline & \multicolumn{2}{c}{ PLA } & \multicolumn{2}{c}{ EPA } & \multicolumn{2}{c}{ Vit-D } \\
& Pre-to-Post & Pre-to-Post2 & Pre-to-Post & Pre-to-Post2 & Pre-to-Post & Pre-to-Post2 \\
\hline Brachial Artery Diameter & $1.0 \pm 14.7$ & $3.7 \pm 10.4$ & $2.0 \pm 10.8$ & $2.4 \pm 9.4$ & $0.7 \pm 8.2$ & $3.6 \pm 6.5$ \\
Resistance Index (RI) & $-4.6 \pm 30.6$ & $1.2 \pm 20.7$ & $-5.2 \pm 15.1$ & $-8.3 \pm 9.1$ & $-0.9 \pm 15.1$ & $-0.9 \pm 15.1$ \\
Flow by Diameter (FbD) & $-14.6 \pm 31.4$ & $-8.8 \pm 50.6$ & $-7.3 \pm 8.7$ & $-12.9 \pm 9.0$ & $-9.5 \pm 34.5$ & $29.5 \pm 15.5$ \\
Heart Rate (HR) & $-3.5 \pm 11.0$ & $-2.4 \pm 6.9$ & $4.0 \pm 12.1$ & $6.1 \pm 15.7$ & $4.3 \pm 16.3$ & $2.3 \pm 14.9$ \\
\hline
\end{tabular}

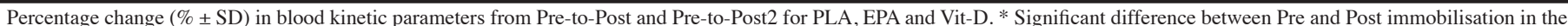
PLA group. $\uparrow$ Significant difference in $\%$ change between groups.

our assessment of resting arterial blood flow (diameter, RI and $\mathrm{FbD}$ ) revealed no significant changes in response to immobilisation; however, we report resting and not reactive blood flow and as such were less likely to see any effect (11). The lack of change in muscle fatigability, however, goes hand in hand with the absence of vascularisation-related alterations. Recently, higher circulating concentrations of 1,25-dihydroxyvitamin $\mathrm{D}$ have been associated with a higher risk of hypertension (42). The authors suggested that the vitamin $\mathrm{D}$-induced increase in calcium absorption could promote vascular calcification, which in turn could lead to increased arterial stiffness and greater hypertension risk. In the current study, vitamin D supplementation did not impact on the measured resting arterial blood flow parameters, however, in the current study this was a short duration supplementation that may not have resulted in comparable increases in circulating concentrations of 1,25-dihydroxyvitamin D. The lack of impact of EPA supplementation on the measured resting arterial blood flow parameters in the current study, concurs with recent findings, that higher serum biomarkers of $\omega-3$ consumption, may not impact on future blood pressure (43).

\section{Conclusion}

In summary, upper limb immobilisation resulted in a decrease in elbow isometric and isokinetic torque, with no observed effect on co-contraction, muscle fatigability or resting blood flow. We observed no significant effect of EPA or vitamin D supplementation on any of these parameters. Despite greater relative decreases in torque than in tissue composition (Part A), there is no significant effect of EPA or vitamin D supplementation on the decreases in torque. It would appear that muscle function might be a less sensitive marker of the effectiveness of a supplement against the impact of immobilisation than tissue composition.

Ethics declaration: All experimental procedures were conducted in accordance with the guidelines in the Declaration of Helsinki and approved by the Ethics Committee of Manchester Metropolitan University.

Acknowledgements: The authors thank HEAL (Health, Exercise and Active Living Research Centre) for funding the study. We would also like to thank the participants for their time and persistence with the study.
Conflict of Interest Disclosures: The authors do not have any conflicts of interest.

\section{References}

1. Berg HE, Larsson L, Tesch PA. Lower limb skeletal muscle function after 6 wk of bed rest. J Appl Physiol, 1997;82:182-8.

2. Clark BC, Fernhall B, Ploutz-Snyder LL. Adaptations in human neuromuscular function following prolonged unweighting: I. Skeletal muscle contractile properties and applied ischemia efficacy. J Appl Physiol, 2006;101:256-63.

3. Miles MP, Clarkson PM, Bean M, Ambach K, Mulroy J, Vincent K. Muscle function at the wrist following $9 \mathrm{~d}$ of immobilization and suspension. Med Sci Sports Exerc, 1994;26:615-23.

4. Vaughan VG. Effects of upper limb immobilization on isometric muscle strength, movement time, and triphasic electromyographic characteristics. Phys Ther, 1989;69:119-29.

5. Miles MP, Heil DP, Larson KR, Conant SB, Schneider SM. Prior resistance training and sex influence muscle responses to arm suspension. Med Sci Sports Exerc, 2005;37:1983-9.

6. Yue GH, Bilodeau M, Hardy PA, Enoka RM. Task-dependent effect of limb immobilization on the fatigability of the elbow flexor muscles in humans. Exp Physiol, 1997;82:567-92.

7. Knaflitz M, Merletti R, De Luca CJ. Inference of motor unit recruitment order in voluntary and electrically elicited contractions. J Appl Physiol, 1990;68:1657-1667.

8. Soderberg GL, Knutson LM. A guide for use and interpretation of kinesiologic electromyographic data. Phys Ther, 2000;80:485-98.

9. Gayeski TE, Honig CR. Direct measurement of intracellular O2 gradients; role of convection and myoglobin. Adv Exp Med Biol, 1983;159:613-21.

10. Henriksson J, Reitman JS. Time Course of Changes in Human Skeletal Muscle Succinate Dehydrogenase and Cytochrome Oxidase Activities and Maximal Oxygen Uptake with Physical Activity and Inactivity. Acta Physiol Scand, 1977;99:91-97.

11. Shoemaker JK, Hogeman CS, Silber DH, Gray K, Herr M, Sinoway LI. Head-downtilt bed rest alters forearm vasodilator and vasoconstrictor responses. J Appl Physiol, 1998;84:1756-62.

12. Barcroft H, Millen JL. The blood flow through muscle during sustained contraction. J Physiol, 1939;97:17-31.

13. Stebbings GK, Morse CI, McMahon GE, Onambele GL. Resting Arterial Diameter and Blood Flow Changes With Resistance Training and Detraining in Healthy Young Individuals. J Athl Train, 2013;48:209-219.

14. D'Antona G, Pellegrino MA, Adami R, Rossi R, Carlizzi CN, Canepari M, Saltin B, Bottinelli R. The effect of ageing and immobilization on structure and function of human skeletal muscle fibres. J Physiol, 2003;552:499-511.

15. Sayer AA, Syddall H, Martin H, Patel H, Baylis D, Cooper C. The developmental origins of sarcopenia. J Nutr Health Aging, 2008;12:427-432.

16. Morley JE, Baumgartner RN, Roubenoff R, Mayer J, Nair KS. Sarcopenia. J Lab Clin Med, 2001;137:231-243.

17. Marcell TJ. Sarcopenia: causes, consequences, and preventions. J Gerontol A Biol Sci Med Sci, 2003;58:M911-6.

18. Dock W. The evil sequelae of complete bed rest. Journal of the American Medical Association, 1944;125:1083-1085.

19. Moylan KC, Binder EF. Falls in Older Adults: Risk Assessment, Management and Prevention. Am J Med, 2007;120:493.e1-493.e6.

20. Ceglia L, Harris SS. Vitamin D and Its Role in Skeletal Muscle. Calcif Tissue Int, 2012;92:151-162.

21. Ross CA, Taylor CL, Yaktine AL, Del Valle HB. Dietary Reference Intakes for Adequacy: Calcium and Vitamin D, in Dietary Reference Intakes for Calcium and Vitamin D, Ross CA, et al., Editors., The National Academies Press: Washington, DC. $2011 ; 345-402$. 


\section{OMEGA-3 FATTY ACIDS AND VITAMIN D IN IMMOBILISATION}

22. Stewart CE, Rittweger J. Adaptive processes in skeletal muscle: molecular regulators and genetic influences. J Musculoskelet Neuronal Interact, 2006;6:73-86.

23. Grundberg E, Brandstrom H, Ribom EL, Ljunggren O, Mallmin H, Kindmark A Genetic variation in the human vitamin D receptor is associated with muscle strength, fat mass and body weight in Swedish women. Eur J Endocrinol, 2004;150:323-8.

24. Bischoff HA, Stahelin HB, Dick W, Akos R, Knecht M, Salis C, Nebiker M, Theiler R, Pfeifer M, Begerow B, Lew RA, Conzelmann M. Effects of vitamin D and calcium supplementation on falls: a randomized controlled trial. J Bone Miner Res, 2003; $18: 343-51$

25. A Report of the Panel on Macronutrients, Subcommittees on Upper Reference Levels of Nutrients and Interpretation and Uses of Dietary Reference Intakes, the Standing Committee on the Scientific Evaluation of Dietary Reference Intakes. Dietary Fats: Total Fat and Fatty Acids, in Dietary Reference Intakes for Energy, Carbohydrate, Fiber, Fat, Fatty Acids, Cholesterol, Protein, and Amino Acids (Macronutrients), A Report of the Panel on Macronutrients, Subcommittees on Upper Reference Levels of Nutrients and Interpretation and Uses of Dietary Reference Intakes, and the Standing Committee on the Scientific Evaluation of Dietary Reference Intakes, Editors., The National Academies Press: Washington, DC. 2005;422-541.

26. Magee P, Pearson S, Allen J. The omega-3 fatty acid, eicosapentaenoic acid (EPA), prevents the damaging effects of tumour necrosis factor (TNF)-alpha during murine skeletal muscle cell differentiation. Lipids Health Dis, 2008;7:24.

27. Houghton D, Onambele GL. Can a standard dose of eicosapentaenoic acid (EPA) supplementation reduce the symptoms of delayed onset of muscle soreness? J Int Soc Sports Nutr, 2012;9:2.

28. Grosset JF, Onambele-Pearson G. Effect of foot and ankle immobilization on le and thigh muscles' volume and morphology: a case study using magnetic resonance imaging. Anat Rec (Hoboken), 2008;291:1673-83.

29. de Boer MD, Selby A, Atherton P, Smith K, Seynnes OR, Maganaris CN, Maffulli $\mathrm{N}$, Movin T, Narici MV, Rennie MJ. The temporal responses of protein synthesis, gene expression and cell signalling in human quadriceps muscle and patellar tendon to disuse. J Physiol, 2007;585:241-51.

30. Ferrando AA, Lane HW, Stuart CA, Davis-Street J, Wolfe RR. Prolonged bed rest decreases skeletal muscle and whole body protein synthesis. Am J Physiol, 270:E627-33.

31. Hermens HJ, Freriks B, Disselhorst-Klug C, Rau G. Development of recommendations for SEMG sensors and sensor placement procedures. Journal of Electromyography and Kinesiology, 2000;10:361-374.

32. Clark DJ, Fielding RA. Neuromuscular contributions to age-related weakness. J Gerontol A Biol Sci Med Sci, 2012;67:41-7.
33. de Araujo RC, Tucci HT, de Andrade R, Martins J, Bevilaqua-Grossi D, de Oliveira AS. Reliability of electromyographic amplitude values of the upper limb muscles during closed kinetic chain exercises with stable and unstable surfaces. J Electromyogr Kinesiol, 2009; 19:685-94

34. Fukuda TY, Echeimberg JO, Pompeu JE, Garcia L, Paulo R, Garbelotti S, Gimenes RO, Apolinario A. Root mean square value of the electromyographic signal in the isometric torque of the quadriceps, hamstrings and brachial biceps muscles in female subjects. Journal of Applied Research, 2010;10:32-39.

35. Solomonow M, Baratta R, Bernardi M, Zhou B, Lu Y, Zhu M, Acierno S. Surface and wire EMG crosstalk in neighbouring muscles. J Electromyogr Kinesiol, $1994 ; 4: 131-42$

36. Bogdanis GC. Effects of Physical Activity and Inactivity on Muscle Fatigue. Front Physiol, 2012;3:142.

37. Delp MD, Colleran PN, Wilkerson MK, McCurdy MR, Muller-Delp J. Structural and functional remodeling of skeletal muscle microvasculature is induced by simulated microgravity. Am J Physiol Heart Circ Physiol, 2000;278:H1866-73.

38. Louisy F, Schroiff P, Guell A. Changes in leg vein filling and emptying characteristics and leg volumes during long-term head-down bed rest. J Appl Physiol, 1997;82:1726-33.

39. Convertino VA, Doerr DF, Stein SL. Changes in size and compliance of the calf after 30 days of simulated microgravity. J Appl Physiol, 1989;66:1509-12.

40. Pawelczyk JA, Zuckerman JH, Blomqvist CG, Levine BD (2001) Regulation of muscle sympathetic nerve activity after bed rest deconditioning. Am J Physiol Heart Circ Physiol, 2001;280:H2230-9.

41. Takenaka K, Suzuki Y, Kawakubo K, Haruna Y, Yanagibori R, Kashihara H, Igarashi T, Watanabe F, Omata M, Bonde-Petersen F, et al. Cardiovascular effects of 20 days bed rest in healthy young subjects. Acta Physiol Scand Suppl, 1994;616:5963

42. van Ballegooijen AJ, Gansevoort RT, Lambers-Heerspink HJ, de Zeeuw D, Visser M, Brouwer IA, Kema IP, de Borst MH, Bakker SJ, Joosten MM. Plasma 1,25-Dihydroxyvitamin D and the Risk of Developing Hypertension: The Prevention of Renal and Vascular End-Stage Disease Study. Hypertension, 2015;66:563-70.

43. Nyantika AN, Tuomainen TP, Kauhanen J, Voutilainen S, Virtanen JK. Serum longchain omega-3 polyunsaturated Fatty acids and future blood pressure in an ageing population. J Nutr Health Aging, 2015;19:498-503. 